\title{
A informação como agente de mudanças nas organizações
}

\section{Information as an Agent of Change in Organization}

\section{Francisco Carlos Paletta}

ORCID:http://orcid.org/0000-0002-4112-5198 Doutor em Tecnologia Nuclear pela Universidade de São Paulo

Professor e pesquisador na Universidade de São Paulo fcpaletta@usp.br

\section{Greicyene Hamaguchi Ueki}

ORCID:https://orcid.org/0000-0001-9819-2431

Graduanda do curso de Biblioteconomia da Universidade de São Paulo greicyene.ueki@usp.br

RESUMO: A partir de análise qualitativa de levantamento bibliográfico o estudo propõe uma discussão sobre o uso da informação nos processos de mudanças nas organizações. A análise busca avaliar o uso de informação como agente de mudança nas organizações no contexto da era digital.

PALAVRAS-CHAVE: Informação. Recuperação da Informação. Confiabilidade da Informação. Agente de Mudanças. Era Digital.

ABSTRACT: From a qualitative analysis of bibliographic survey the study proposes a discussion on the use of information in the processes of change in organizations. The analysis seeks to evaluate the use of information as a source of mediation as well as the use of information as an agent of change to produce productive transformations in the digital age.

KEYWORDS: Information. Information Retrieval. Reliability of Information. Change Agent. Digital Era. 


\section{Introdução}

As várias possibilidades para uso da informação abrem muitas oportunidades e, ao mesmo tempo, desafios. A administração, seja de um centro de informação tradicionalmente concebido como a biblioteca ou de qualquer outra unidade que tenha como objetivo a geração de valor para a sociedade e a produção de alto volume informacional, impacta nas decisões para a melhor gestão dos recursos finitos e para garantia de sobrevivência no mercado.

Os desafios provenientes da produção e do consumo de informações em meio digital atingem não apenas as organizações, mas também a sociedade civil como um todo. O que também gera necessidade de uma melhora na leitura de notícias e cuidados com excesso de produção de material informacional que transforma o usuário de informação com uma dupla função no ciberespaço (consumidor e produtor de informação).

Pensar a mudança como um caminho sob o qual organizações e pessoas passam ao longo de suas vidas, e a forma como elas lidam com isso nos ajuda a refletir o momento que se vivencia e o porquê o pensamento de mudança altera de forma substancial o mindset $^{1}$ das pessoas.

1

Conjunto de atitudes mentais que influencia diretamente nos nossos comportamentos e pensamentos

Com base nessa perspectiva, este estudo tem como objetivo avaliar o uso de informação como agente de mudança nas organizações no contexto da era digital. Como procedimento metodológico realizou-se um levantamento bibliográfico de produções científicas da área de Ciência da Informação e de Administração.

\section{Informação como base para mudanças}

A informação é um item básico que auxilia todas as ciências. "Etimologicamente, a palavra informação vem do latim por meio do francês unindo o termo “informar" que pode significar "dar forma à mente", com o sufixo "ção" que remete 
a uma ação; significando moldagem ou treinamento da mente" (LOGAN, 2012, p.102). Com a definição de Logan pensa-se não apenas na forma, mas também na ação que a informação tem no meio.

Pensar que uma sociedade onde a conexão em redes faz parte de sua força motriz, em um primeiro momento é possível imaginar que ela buscaria um consenso de ideias e finalidades, buscando um objetivo comum. Entretanto, nesse cenário os indivíduos se voltam cada vez mais em torno do que acreditam ou do que são, surgindo assim processos de intolerância em relação às ideias que não compactuam.

\section{Confiabilidade da Informação}

A informação como instrumento para o processo de decisão mostra a importância da sua segurança. No cenário social, o fenômeno das fake news representa a fragilidade com que a segurança de informações está em jogo. Ademais, é importante pensar também no contexto cultural onde a sociedade não é apenas consumidora de informação mas também produtora de informação, até mesmo como resposta a momentos históricos onde o direito a pensar a cultura não era possível a todos já que uma cultura dominava as demais.

Nesse contexto a informação que permite a geração de novos conhecimentos, que em teoria teriam seu valor significado como intangível, acaba por torna-se uma informação estratégica para sobrevivência com valor e prazo de validade, a exemplo dos insiders americanos, que são os mais conhecidos como consequência de sua força econômica, e que no Brasil observamos sua atuação de forma ativa no circuit breaker da bolsa em maio de 2017.

\section{Busca, Acesso e Apropriação}

A apropriação surge da busca de retirar a barreira inicial, de descobrimento, de se firmar uma relação atitudinal sob o que é apresentado, diferentemente de uma 
visão onde apenas um fala e outros escutam.

As tecnologias são um importante aliado na disseminação e democratização ao acesso à informação. A velocidade como a tecnologia se altera ao mesmo tempo que gera oportunidades, também gera exclusão- considerando que ao mesmo tempo em que o acesso através da tecnologia é extremamente aberto também se apresenta no lado mais sombrio, onde acabam-se por excluir os indivíduos que não estiverem no inseridos no contexto tecnológico.

A informação para os indivíduos permite que a sua cidadania seja exercida e que ele consiga se fazer ouvir e expor suas ideias. A preocupação com a alfabetização informacional nesse contexto apresentado busca melhorar essa relação do indivíduo com a informação, sendo a preocupação em usar a tecnologia de informação e comunicação primordial, e neste ponto que outras necessidades informacionais surgem sendo importante identificar os problemas de informação e como fazer uso de uma informação de qualidade ou não.

As tecnologias de acesso em rede são ao mesmo tempo potencializadoras e inovadoras se comparado com a história da comunicação da humanidade. As barreiras geográficas estão excluídas, haja vista a dinamicidade e flexibilidade no processo de comunicação em meio digital. O manual de Oslo orienta sobre a inovação, sua construção em processo de entrega de valor, onde uma visão tradicional já não resolve mais a complexidade dos processos envolvidos, já que o contexto "não funciona em economias constituídas por pessoas de diferentes perfis, em que cada uma delas tem seus próprios desejos, preferência e critérios de compras" (KOTLER, KELLER, 2012, p.38). É nesse contexto ambiente que a inovação precisa acontecer, onde as organizações se desenvolvem sabendo que a informação funciona como um componente intrínseco em quase todos os processos e na tomada de decisão.

O processo de escolhas desde mais simples ou não, tem início na inteligência emocional que é "capacidade de uma pessoa de ser autoconsciente do seu estado afetivo (reconhecer suas próprias emoções como as sente), detectar as emoções nos outros e administrar as pistas e as informações transmitidas pela emoção" 
(ROBBINS, JUDGE, SOBRAL, 2010, p. 105), e essas habilidades cognitivas são exploradas nas agências de marketing e em ambientes onde a decisão das pessoas tem influência em seu modo de operação. O efeito da informação que se recebe passa por um complexo sistema emocional, que tem raízes no processo de apelo intuitivo.

Todos estes estudos são importantes, considerando que "cada vez mais, os pesquisadores estão descobrindo que os sentimentos e as emoções têm efeitos importantes na tomada de decisão" (ROBBINS, JUDGE, SOBRAL, 2010, p.108), todavia, os "pesquisadores concluíram que a intensidade dos sentimentos condiciona o processo de decisão" (ROBBINS, JUDGE, SOBRAL, 2010, p.108). Esses sentimentos, por sua vez, são identificados a partir de informações que são processadas, organizadas e analisadas.

\section{Relação entre o agente de mudança e a informação}

O termo "agente de mudança" tem sido estudado pelas ciências comportamentais, cujo conceito diz respeito a "[...] um profissional que influencia decisões para inovação, numa direção considerada desejável pela agência de mudanças". (HESKETH, OTTAWAY, 1979, p. 29). Sendo assim a questão de fatores comportamentais têm influência na tomada de decisões, pois tanto a tecnologia quanto as pessoas estão presentes no processo de mudanças. A busca por mudanças contempla para os administradores funções como aprendizagem e desenvolvimento de novas competências sendo assim "deve ser um agente de mudanças e transformação na organização" (CHIAVENATO, 2014, p.6). Nesse contexto, a palavra transformação já traz consigo uma ideia da profundidade em relação ao que o agente de mudanças pode causar na organização em razão das transformações ocorridas nesse cenário.

Neste contexto, a previsibilidade sobre o que futuro se apresenta como de difícil compreensão já que o cenário está envolvido em vários fatores de incerteza. O Quadro 1 apresenta as megatendências com base nas transformações em curso: 
Quadro 1 - Megatendências no mundo moderno segundo Naisbitt

\begin{tabular}{|c|c|c|}
\hline DE & PARA & ALTERAÇÃO \\
\hline $\begin{array}{l}\text {-Sociedade Industrial } \\
\text {-Tenologia Simples } \\
\text {-Economia Nacional } \\
\text {-Curto Prazo } \\
\text {-Democracia Representativa } \\
\text {-Hierarquias } \\
\text { - Opção Dual } \\
\text {-Centralização } \\
\text {-Ajuda Institucional }\end{array}$ & $\begin{array}{l}\text {-Sociedade da Informação } \\
\text {-Tecnologia Sofisticada } \\
\text {-Economia Mundial } \\
\text {-Longo prazo } \\
\text {-Democracia Participativa } \\
\text {-Comunicação Lateral } \\
\text {-Opção Múltipla } \\
\text {-Descentralização } \\
\text {-Autoajuda }\end{array}$ & $\begin{array}{l}\text {-Inovação e Mudança } \\
\text { •Maior Eficiência } \\
\text { - Globalização e Competitividade } \\
\text { •Visão de Negócio } \\
\text {-Pluralismo e Participação } \\
\text {-Democratização e Visibilidade } \\
\text {-Visão Sistêmica e Contingencial } \\
\text {-Incerteza e Imprevisibilidade } \\
\text {-Serviços Diferenciados }\end{array}$ \\
\hline
\end{tabular}

Fonte: Chiavenato (2014, p.88)

A informação trata sobre a forma de algo que irá se modificar e o agente de mudanças é o responsável não apenas por gerir, mas, principalmente, por garantir que as mudanças aconteçam.

A Teoria do prospecto ou Prospect Theory, de Amos Tverky e Daniel Kahneman, apresentam como as crenças podem ser prejudiciais em situações de tomada de decisões. Essa teoria apresenta as decisões econômicas e alerta para situações de perda de capital, em que, pensando de forma lógica, as decisões deveriam tender para a cautela. Nesse sentido, o que se observa é justamente o contrário, ou seja, as pessoas ficam mais confiantes acreditando em certas crenças do mercado (seja por figuras, por análise de price action, por exemplo) ou com base em certas notícias que estão para sair ou que já saíram, mas se esquecem que na grande maioria o mercado financeiro já precificou aquele faixa de preço observando o ambiente macroeconômico. Nessa mesma linha de pensamento, a autora Vera Rita de Mello Ferreira lança em seu livro uma pergunta "as emoções surgiram, no homem, muito antes do que a razão e, ainda hoje, podem ter muito poder sobre nós do que nosso lado lógico e racional, que é bem mais recente?” (FERREIRA, 2011, p.34). Ao longo do livro a autora apresenta vários exemplos de como as pessoas lidam com a responsabilidade de seus atos, isso tudo porque certas decisões financeiras podem ser extremamente prejudiciais para a vida das pessoas. 


\section{Cultura e midia na era digital}

Pensar em cultura e em mídia na era digital com a quantidade de informações produzidas, onde o papel de consumidor e produtor se esbarram, se configura como uma das grandes e complexas questões que a sociedade da informação precisa enfrentar. A grande quantidade de informações lançadas na rede diariamente leva em conta tanto a pluralidade cultural como as fake news. Fato que mesmo sendo pensado como produzido para levar uma notícia falsa ao público, que terá acesso àquela informação, suas consequências podem ser complicadas e de difícil consenso, pois as fake news influenciam e expõem a dificuldade na capacidade das pessoas tomarem de decisões, atingindo assim, justamente princípios fundamentais e necessários para vida em sociedade.

Pensar a cultura nesse momento de mundialização, para que se discuta o que efetivamente as tecnologias da informação estão fazendo e como elas podem contribuir de acordo com as características culturais de cada lugar, pode gerar uma ideia de certa homogeneidade sendo importante o cuidado na forma como a economia, a informação e a cultura se misturam e geram distorções e desigualdades, conforme entende-se que "As diferenças socioculturais entre países e regiões, convertidas em assimetrias e desigualdades, exigem considerar a tensão entre a universalidade do conhecimento e as condições particulares de produção e enunciação dos saberes" (CANCLINI, 2009, p.187) a difusão da multiplicidade cultural, e versar acerca da socialização dos saberes em uma concepção democrática são temas para pensar escolhas necessárias de modo a preencher lacunas e dúvidas geradas na transmissão de informação.

\section{Personalização do serviço sem pessoas}

O serviço de referência digital acontece independentemente do espaço físico, seja em uma biblioteca tradicional ou em um centro de informação especializado, 
uma vez que o serviço ocorre em decorrência de um avanço tecnológico, sendo a tecnologia uma mediadora inicial desta relação. Assim acabaria por gerar um paradoxo entre a personalização e o da proximidade, dentro do contexto de serviço de referência digital.

Diferentemente do serviço de referência presencial, onde as habilidades cognitivas e demandas informacionais são percebidas no momento do atendimento e de acordo com a experiência do profissional, no serviço de informação digital essa relação não acontece. Se usuário estiver em um chat que use algoritmos que respondem as perguntas antes de acionar um atendimento de um profissional, essa busca pode ser conflituosa ao mesmo tempo que pode ser enriquecedora.

Tanto o serviço de referência presencial como o digital são imbuídos na preocupação em uma recuperação eficiente de modo que suas buscas possam gerar conhecimentos, baseado em uma relação de proximidade com o usuário. O que pode tornar difícil esse desenvolvimento é o fato de que o acesso às tecnologias da informação não acontecem de forma igualitária, considerando que o acesso às tecnologias de informação não contempla apenas a missão de informar, mas de gerar riquezas e trocas de dados "em um mundo onde a mudança acontece a uma velocidade crescente, a informação e a tecnologia precisam ser utilizadas para obter plena vantagem" (CHIAVENATO, 2014, p.99).

\section{A Organização no contexto da mudança}

A compreensão dos aspectos organizacionais ligados ao sucesso ou fracasso empresarial em grandes corporações têm como fator determinante a informação, e assim a sua importância gera a necessidade do cuidado com a memória organizacional, que cuida das informações não pensando apenas em termos de arquivologia ou biblioteconomia, mas sim pensando na informação como força motriz para a produção de novos conhecimentos.

O enfrentamento de desafios faz parte do cotidiano e são mais per- 
ceptíveis em uma sociedade em rede onde o conhecimento, a informação, lazer, trabalho vários setores se misturam, ficando difícil a divisão de momentos, sabendo que o trabalho consome boa parte do tempo das pessoas e tecnologias muitas invadem o descanso. Assim muitos estão sob constante acesso às linguagens. As linguagens possibilitam as mudanças e principalmente auxiliam no seu processo de divulgação, de modo, que as mudanças em sua maioria, têm como características o barulho e o movimento. A decisão de uma mudança, tem como norte uma melhora ou transformação de algo já consolidado, por isso o entendimento que este movimento dinâmico tem como base a ansiedade dos participantes da organização no processo de mudança.

Uma organização inserida no contexto de redes de informação, mesmo que não inicie uma mudança organizacional será de algum modo influenciada para adoção de processos de mudanças observados no macroambiente. Também é importante que se veja a organização como uma entidade com finalidades sociais, o que torna necessário o acesso às mudanças e informações que estão circulando.

\section{Considerações finais}

Repensar e melhorar a forma como o profissional bibliotecário é visto no mercado de trabalho certamente será um dos grandes desafios que os futuros profissionais precisarão enfrentar, entretanto acredita-se que esse desafio é imbuído de oportunidades.

Assim como em várias áreas do saber, a importância de se aliar às tecnologias da informação e comunicação, não é apenas um diferencial, mas sim um fator determinante no que tange à sobrevivência no mercado de trabalho.

O profissional que exercer a função de agente de mudanças, será um profissional que contará com habilidades interpessoais, cognitivas e de administração. Ao pensar em um sujeito que tenha uma concepção de si mesmo como sujeito protagonista, em algum momento será um dos objetivos do profissional da informação, e 
para que isso aconteça, será necessário que o profissional exerça a função de agente de mudanças usando a informação como força de transformação e mudança.

A cultura, em sentido amplo, a organização, as formas de relacionamento, a mídia digital e a segurança da informação são fatores que influenciam, tanto de forma positiva como negativa, nas mudanças sobre as quais a sociedade passa e passará. Neste contexto os mais diversos profissionais terão que de algum modo lidar com a informação e as consequências que a informação poderá propiciar entre os que estiverem inseridos no contexto.

\section{Referências:}

CANCLINI, N. G. Sociedade do conhecimento: a construção intercultural do saber. In: CANCLINI, N. G. Diferentes, desiguais, desconectados: mapas da interculturalidade. Rio de Janeiro: Editora UFRJ, 2009.

CHIAVENATO, I. Administração nos novos tempos: novos horizontes em administração. São Paulo: Manole, 2014.

FERREIRA, V. R. de M. Decisões econômicas: você já parou para pensar? São Paulo: Évora, 2011.160 p.

HESKETH, J. L. OTTAWAY, R. N. Características dos agentes de mudança. Rev. adm. Empresa, São Paulo, v. 19, n. 3, p. 27-33, Sept. 1979. Disponível em: http://www.scielo.br/pdf/rae/v19n3/v19n3a03.pdf. Acesso em: 11 jun. 2018.

KOTLER, P., KELLER, K.L. Administração de marketing. Tradução: Sandra Midori Yamamoto. São Paulo: Pearson education, 2012. 765p.

LOGAN, R.K. O que é informação? A propagação da organização na biosfera, na simbolosfera, na tecnosfera e econosfera. Tradução: Adriana Braga. Rio de Janeiro: Contraponto: PUC-Rio, 2012.

ROBBINS, S.P. JUDGE, T.A. SOBRAL, F. Comportamento organizacional: teoria e prática no contexto brasileiro. Tradução: Rita de Cássia Gomes. 14 ed. São Paulo: Pearson Prentice hall, 2010. 